\title{
4 \\ LA SECCIÓN DISCUSIÓN EN ARTíCULOS DE CIENCIAS AGRARIAS: LEGITIMACIÓN Y DEFENSA DE RESULTADOS
} THE DISCUSSION SECTION IN AGRICULTURAL SCIENCES

RESEARCH ARTICLES: LEGITIMATION AND DEFENSE OF THE RESULTS

Estela Inés Moyano

estelaimoyano@gmail.com / Universidad Nacional de General Sarmiento Universidad Nacional Guillermo Brown Universidad de Flores Argentina 


\section{RESUMEN}

El objetivo de este trabajo es determinar si existen patrones comunes de estructura esquemática y uso predominante de recursos lingüísticos en las Discusiones de artículos científicos en el área de las Ciencias Agrarias. Para ello, se analizó manualmente un corpus de cuatro textos desde la perspectiva de género en el marco de la lingüística sistémico-funcional. Como resultado, se encontraron dos patrones de realización, representados por dos géneros diferentes. Uno de ellos es la garantía de la investigación, género que se propone legitimar los resultados hallados en el trabajo, de suerte de persuadir a los lectores y garantizar que resultan pertinentes para incorporarse al cuerpo de conocimiento disciplinar en el área de estudio. El segundo es la justificación analítica, que se propone lograr la alineación de los lectores en defensa de una Tesis propuesta, de manera explícita o implícita, desde la Introducción del trabajo. Los recursos discursivos más destacados en los textos para lograr este propósito resultaron ser los de la PERIODICIDAD, que permite organizar la información en el texto, los de CONJUNCIÓN, particularmente realizados como metáforas lógicas y los de VALORACIÓN en el discurso, particularmente del subsistema de COMPROMISO. Pese a la justificación del tamaño del corpus basado en el concepto de instanciación, los resultados obtenidos deben ser considerados preliminares hasta tanto pueda explorarse un número mayor de textos.

\section{PALABRAS CLAVE}

$>$ discurso científico

$>$ Ciencias Agrarias

$>$ sección Discusión de artículos de investigación

$>$ género

$>$ recursos semántico-discursivos 


\section{ABSTRACT}

The aim of this paper is to recognize patterns of schematic structure and relevant linguistic resources in Discussions of research articles in the discipline of Agricultural Sciences. With this purpose, a corpus of four texts was analysed manually from the perspective of genre in systemic functional linguistics. The results show two patterns of realization in two different genres. The first is the warranty of the research, which purpose is to legitimate the results found in order to persuade the readers of their value and to guarantee that they are pertinent to be incorporated to the body of disciplinary knowledge. The second is the analytic exposition, which purpose is obtaining the alignment of the readers to the Thesis proposed in an explicit or implicit way in the Introduction of the paper. The discourse-semantic resources found as relevant were those from the system of PERIODICITY, which organize the information in the text, those of CONJUNCTION, particularly realised as logical metaphors and those of APPRAISAL, especially from the subsystem of ENGAGEMENT. Although the corpus has been justified by the concept of instantiation, the results obtained are considered preliminary until more research can be done.

\section{KEYWORDS}

$>$ scientific discourse

$>$ Agricultural Sciences

$>$ Discussion section of research articles

$>$ genre

$>$ discourse-semantic resources 


\section{INTRODUCCIÓN}

El artículo de investigación o artículo científico es un documento que tiene como propósito social construir nuevo conocimiento en un campo disciplinar y persuadir a la comunidad discursiva acerca de que ese conocimiento merece un espacio en la disciplina en cuestión. El interés que su estudio tiene en el marco de la lingüística sistémico-funcional (LSF) consiste en establecer de qué manera el texto se organiza para lograr estos propósitos y mediante qué recursos lingüísticos se manifiestan tanto la construcción de nuevo conocimiento como el modo en que se lleva a cabo la búsqueda de acuerdos con la audiencia, en este caso, la comunidad disciplinar. Objetivos de este tipo son de largo alcance y requieren todavía de mucho trabajo de investigación, incluyendo el estudio del artículo y sus secciones así como comparaciones entre artículos de diferentes disciplinas.

Cabe señalar que existen estudios que se han ocupado del artículo científico entendido como género discursivo desde diferentes corrientes, como la Nueva Retórica (Bazerman, 1988 (2000)) o la denominada Lengua para Propósitos Específicos (LPE) (Swales, 1990, 2004; Bhatia, 1993). Esta última línea, con el propósito de elaborar descripciones que puedan servir a fines pedagógicos, identifican no solo la estructura del artículo sino algunos recursos lingüísticos relevantes para su construcción. Estos trabajos han coincidido en reconocer, basándose en la utilización de subtítulos en los textos explorados, que el artículo de investigación se compone, en general, de cuatro secciones diferentes: Introducción, Métodos, Resultados y Discusión. Las iniciales de estos subtítulos conforman la sigla IMRD, que se utiliza para dar nombre a esta estructura. Asimismo, han señalado qué tipo de contenido y propósito tienen cada una de estas partes formales del artículo. Entre estos estudios, se distingue el realizado en el marco de la LSF por Korner, McInnes y Rose (2007), que dedican un apartado al estudio del artículo en Ingeniería para estudiar, no solo su estructura sino el modo en que los recursos lingüísticos producen significado. En este último sentido, Hyland (1999) se concentra en estudiar la interacción de voces en el discurso científico, a fin de señalar la búsqueda de reconocimiento de los propios hallazgos.

Por otra parte, existen trabajos que se han propuesto caracterizar las secciones por su función en relación con el artículo completo. Por ejemplo, diversos autores de la corriente LPE han abordado la sección Discusión, tanto en ciencias naturales 
y exactas como en las sociales y humanas (Peng, 1987; Hopkins \& Dudley-Evans, 1988; Holmes, 1997; Peacock, 2002; Basturkmen, 2012). En estos estudios, así como también en otros realizados sobre Discusiones de artículos científicos en español (Ciapuscio \& Otañi, 2002; Puiati de Gómez, 2005), se han reconocido algunos movimientos retóricos obligatorios y otros opcionales, organizados en ciclos recurrentes, poniendo en evidencia una gran variedad de combinaciones, no solo entre disciplinas sino al interior de ellas. Si bien estos resultados han aportado a señalar algunas de las funciones de la sección Discusión, no resultan suficientes para su caracterización lingüística, pues, hasta el momento, son escasos los patrones que emergen con claridad, tanto en lo que hace a la organización de los textos como a los recursos lingüísticos utilizados tratados conjuntamente.

Otros estudios, enmarcados en la LSF, han avanzado sobre secciones como la Introducción de artículos en inglés (Hood, 2010) o la Discusión de artículos en español (Moyano, 2015a). Estos trabajos han permitido formular la hipótesis de que el artículo científico se trata de un macro-género (Martin, 1994; Eggins y Martin, 2003), es decir, de una serie de textos adyacentes — cada uno de los cuales instancia un género elemental- que se combinan para el logro de un propósito más amplio que el de cada uno de ellos. Así, el artículo de investigación se compone de diferentes secciones (IMRD), cada una de las cuales tiene un propósito diferenciado y contribuye al logro del propósito global del texto completo. Atendiendo a las diferentes metas perseguidas por cada sección del artículo de investigación, es relevante para caracterizar lingüísticamente cada una de ellas, la identificación de su estructura esquemática y de los recursos lingüísticos utilizados para su realización, teniendo en cuenta las opciones de los diferentes subsistemas del sistema general del lenguaje. Esto permite sostener la necesidad de su estudio por separado, tratando cada sección como género.

Dentro de este marco teórico, se han producido descripciones de la Discusión en artículos de Microbiología y de Economía elaborados en español (Moyano, 2014; en prensa), que han mostrado que es posible caracterizar la sección como género $y$, en muchos casos, que se manifiesta también como macrogénero, de manera similar a lo hallado por Hood (2010) para las introducciones en inglés. Se abordó también el análisis de la interacción de voces en Discusiones en Sociología y Micobiología (Moyano, 2019), lo que permitió mostrar que cada disciplina maneja de 
manera diferente los recursos lingüísticos para lograr sus propósitos según el tipo de disciplina de que se trate, considerando la diferenciación de Bernstein (1999).

El objetivo de este trabajo es abordar en el marco de la LSF las Discusiones de artículos en Ciencias Agrarias, a fin de determinar la existencia de patrones comunes en su realización, tanto para su estructura esquemática como para los recursos lingüísticos relevantes que le permiten lograr su propósito.

\section{MARCO TEÓRICO}

El marco teórico y metodológico utilizado en este estudio es el modelo estratificado de contexto y lenguaje elaborado por Martin (Martin, 1992; 1999; 2014; Martin \& Rose, 2007, 2008) dentro de los lineamientos generales de la Lingüística Sistémico-Funcional (LSF) (Matthiessen \& Halliday, 2009; Martin, 2013). La elección de este marco se debe a que ofrece elementos teóricos para un análisis lingüístico que permite dar cuenta de los significados construidos en un texto a partir de su mutua dependencia con el contexto social, sin necesidad de tomar como base la intuición del analista ni la interpretación de los usuarios del lenguaje en contextos específicos a partir de investigación etnográfica, como ocurre en las líneas mencionadas antes.

La LSF propone cinco dimensiones para comprender el lenguaje: eje, estratificación, rango, metafunción, instanciación (Halliday y Matthiessen (2009). En lo que respecta a la dimensión eje, se entiende el lenguaje como recurso para la producción de significados que se organizan como sistema de opciones para la producción de mensajes. Así, la interpretación de los significados en el análisis de los textos se hace teniendo en cuenta el sistema lingüístico descripto, de manera que las opciones que se realizan en una instancia tienen valor en relación con las que no se realizan.

En cuanto a los conceptos de estratificación y metafunción ofrecen la posibilidad de establecer la relación entre el texto y su contexto, teniendo en cuenta que las realizaciones lingüísticas son hechas a partir de las opciones sistémicas que cada contexto habilita, es decir, que ofrece como expectativa a los participantes del intercambio. La realización se entiende a través del concepto de redundan- 
cia (Lemke, 1995), que propone que los patrones de significado en un sistema configuran patrones en el otro, de la misma manera que ocurre entre estratos. La estratificación reconoce diferentes niveles de abstracción en el contexto y el lenguaje. En el contexto, Martin (2014) identifica dos estratos, el género y el registro; en el lenguaje, la semántica-discursiva, que tiene como unidad el texto; la léxico-gramática, que reconoce como unidad la cláusula; y la fono-grafía, que se centra en unidades como el tono y la tonicidad o en los recursos gráficos del lenguaje escrito. La metafunción tiene que ver con los diferentes tipos de significado que el lenguaje produce para realizar los significados del registro. Como se desarrolla más adelante, las metafunciones son tres y permiten la construcción de mundo, relaciones y texto.

Halliday (2008) explica el concepto de instancia en relación con el sistema general del lenguaje como un mismo fenómeno visto desde diferentes perspectivas. Así, la instancia es la manifestación en un texto de opciones del sistema general del lenguaje habilitadas por el género y el registro. Halliday utiliza para explicar esto la relación análoga entre tiempo y clima, dos maneras diferentes de observar el mismo fenómeno, que permite dar cuenta de las características de tiempo en un día específico en una región climática específica. De esta manera, la construcción del sistema (clima) se puede hacer mediante la observación de un conjunto de instancias (tiempo). Así, una instancia textual adquiere significado en relación con el sistema general del lenguaje, que a su vez puede ser construido a partir de la observación de un conjunto de instancias particulares.

La sección Discusión de artículos de investigación es abordada en este trabajo como género en el marco de la LSF. Martin y sus colaboradores (Martin, 1992; 1999; Martin \& Rose, 2008) definen género como configuración particular de las variables de registro (campo, tenor y modo) que se realizan a través del lenguaje en tres metafunciones a lo largo de tres estratos. El campo se relaciona con la construcción de mundo, la actividad social que se lleva a cabo, teniendo en cuenta las actividades que la configuran. Asimismo, se tienen en cuenta las relaciones taxonómicas entre los ítemes vinculados con esas actividades, ya sea que representen personas, cosas o lugares (Martin, 2020; Doran y Martin, 2021). El tenor construye las relaciones interpersonales entre los participantes de la interacción, teniendo en cuenta las relaciones de poder que se producen entre ellos (Martin, 1992). El modo se vincula con el rol que el lenguaje tiene 
en la interacción, su dependencia del contexto y el grado de abstracción que se construye (Martin y Matruglio, 2020). En cuanto a las metafunciones del lenguaje en el estrato semántico-discursivo que realizan los significados del registro (Martin y Rose, 2007), la metafunción ideacional realiza los significados del campo y genera sistemas de entidades y figuras para construirlos (Hao, 2020; 2021). Asimismo, se ocupa de las relaciones lógicas entre esas actividades (CONJUNCIÓN). La metafunción interpersonal realiza el tenor a través de la selección de opciones de los sistemas de NEGOCIACIÓN, vinculado con el modo en que se produce discursivamente la interacción entre participantes y VALORACIÓN (Martin y White, 2005), que se ocupa de la evaluación que se hace de personas, cosas y conductas y la construcción y negociación de posiciones en el texto. La metafunción textual realiza el modo y se ocupa de la organización de la información en el texto (PERIODICIDAD) y del seguimiento de las entidades en su despliegue (IDENTIFICACIÓN) (Martin y Rose, 2007).

Finalmente, y siguiendo a Martin (2009) y a Martin y Rose (2007), dado que la estratificación explica la realización de significados en los diferentes estratos del lenguaje, al analizar un texto se tienen en cuenta fundamentalmente los sistemas semántico-discursivos para la realización de los significados generados en el registro, pero en los casos en que resulta pertinente, se observa su codificación en la léxico-gramática (Halliday y Matthiessen, 2004), teniendo en cuenta los diferentes rangos, niveles encontrados en los diferentes estratos.

De manera operativa, un género puede entenderse también como una actividad social con un propósito específico, es decir, orientada a una meta (Martin y Rose, 2008). Esta se cumple en pasos o etapas, que conforman lo que se denomina estructura esquemática del género. Por otra parte, los géneros se realizan a través de textos que, según afirma Martin (1994), presentan en general una extensión relativamente reducida. Sin embargo, con mucha frecuencia, algunos de estos textos con metas específicas reconocidas en un ámbito cultural determinado se combinan entre sí para conformar una unidad mayor, que logra de esta manera un propósito global más amplio. Esa unidad, conformada por una combinación de géneros, se denomina macrogénero (Martin 1994; Eggins \& Martin, 2003; Martin \& Rose, 2008), como ya se explicó antes. 


\section{BREVE MARCO METODOLÓGICO}

Como han explicado y ejemplificado Martin y Rose (2007) y Martin (2009), en el tipo de trabajo que se propone a partir de la teoría de género en la LSF, se parte del análisis individual de cada texto, a fin de determinar su estructura esquemática así como los recursos semántico-discursivos que contribuyen a su realización. Para ello, es necesario tener en cuenta los recursos que se destacan en primer plano y los que co-articulan con ellos para la producción de significados, fenómeno que Martin (2008) denominó acople. El criterio, entonces, es identificar, a partir de los sistemas identificados en la teoría, qué recursos lingüísticos trabajan de manera conjunta en el estrato semántico-discursivo y su realización en la léxico-gramática para producir los significados que permiten lograr el propósito social perseguido por el texto bajo análisis.

Por otra parte, interesa generalizar a lo largo de un conjunto de textos para aportar información sobre las características de un género determinado. Según Martin y Rose (2007), esto es posible teniendo en cuenta el concepto de instanciación, que permite llevar a cabo esa caracterización mediante un número reducido de textos. En este sentido, el análisis de ejemplares considerados del mismo género llegan a saturar en la descripción en un número reducido (Vidal, 2020), de manera de poder mostrar qué recursos del sistema general del lenguaje toman relevancia en ese conjunto de instancias, lo que permite identificar los rasgos de un género.

Teniendo esto en cuenta, en el estudio del que aquí se da cuenta se seleccionaron de una revista relevante en el campo de las Ciencias Agrarias cuatro artículos relativos a la producción vegetal. La revista cuenta con el proceso de referato doble ciego, lo que garantiza la aceptación de los trabajos publicados por expertos de la disciplina a partir de criterios establecidos en la comunidad disciplinar y, por lo tanto, los legitima.

Seleccionados los trabajos, se analizó su organización en secciones y se establecieron los criterios para reconocer la Sección Discusión. Solo a partir de allí se inició el proceso de análisis lingüístico para caracterizar los patrones de género instanciados en esas secciones constituyentes del macrogénero artículo de investigación en el campo elegido.

Los pasos propuestos para el análisis implican la separación de los textos en cláusulas, la formulación de una hipótesis acerca del género que el texto instan- 
cia y las etapas en que se realiza. Posteriormente, se lleva a cabo el análisis de los recursos lingüísticos relevantes en el estrato semántico-discursivo y, cuando resulta necesario, su realización mediante recursos del estrato léxico-gramatical.

Entre los recursos semántico-discursivos que resultaron relevantes para el análisis de las Discusiones en Ciencias Agrarias, se destacan la IDEACIÓN y la CONJUNCIÓN, entre los recursos ideacionales, la PERIODICIDAD, entre los textuales y la VALORACIÓN, entre los interpersonales (Martin y White, 2005). La IDEACIÓN hace referencia a los recursos para la construcción de mundo, que vinculan entre sí entidades, actividades y circunstancias, así como las relaciones taxonómicas entre entidades. La CONJUNCIÓN incluye los recursos para establecer relaciones lógicas entre los eventos representados en el texto (conjunción externa) o entre las diferentes partes del discurso (conjunción interna). En los textos analizados, como es altamente frecuente en el discurso científico, se reconocen las metáforas lógicas, es decir, las relaciones lógicas que se realizan mediante recursos léxico-gramaticales diferentes de la conjunción, como los grupos verbales, por ejemplo. La PERIODICIDAD se refiere al conjunto de recursos que permiten la organización del flujo de información en el texto, creando momentos de anticipación y de síntesis, manteniendo el ángulo del campo al que se orienta el discurso o estableciendo cambios en él. Finalmente, la VALORACIÓN incluye los recursos que permiten construir la ACTITUD frente a diferentes entidades (AFECTO para la valoración de personas, JUICIO para la valoración de conductas y APRECIACIÓN para la valoración de objetos); asimismo, permite identificar las fuentes de esas emociones, y, finalmente, la relación entre diferentes posiciones en el discurso, manifestadas a través del subsistema de COMPROMISO (Martin y Rose, 2007; Martin y White, 2005).

Este análisis permite confirmar o rechazar la hipótesis efectuada sobre el género y el reconocimiento del propósito social perseguido por el texto.

\section{ANÁLISIS}

Los artículos de Ciencias Agrarias analizados presentan una estructuración canónica con variantes. Esto significa que, si bien tienen la estructura IMRD, tres de ellos añaden a estas secciones un apartado para Conclusiones. En el artículo 
que no lo presenta, éstas aparecen sin subtitular en el último párrafo de la Discusión. Las Conclusiones, identificadas con subtítulo o no, en esta disciplina están constituidas por la respuesta a los objetivos formulados en la Introducción.

Tal como se señaló para Microbiología (Moyano, 2014), en la sección Discusión de artículos en Ciencias Agrarias también se encuentran varios de los movimientos identificados por Hopkins y Duddley Evans (1988) para Discusiones en Ingeniería y Biología: Declaración de Resultados, Explicación de Resultados (esperados o inesperados), Referencia a Investigaciones Anteriores. Sin embargo, siguiendo el criterio de Moyano (2015a), en este trabajo se trata el conjunto de Discusión más Conclusiones como una unidad consistente en la última sección de cada artículo a fin de mostrar la lógica de la organización de los textos en una estructura esquemática, así como la co-articulación entre recursos semántico-discursivos de diferentes metafunciones. De esta manera, se procura poner en evidencia el propósito social que esta sección crítica del artículo de investigación persigue.

En las Discusiones de artículos de investigación en Ciencias Agrarias, se encuentran al menos dos opciones de género entre las que el autor selecciona de acuerdo con la naturaleza de su trabajo. Ambas, sin embargo, parecen apuntar a la defensa de los resultados obtenidos como aporte a la disciplina, ya sea i) a través de su legitimación por comparación con resultados de otros autores en el mismo campo, ii) a través de su explicación a partir de su coincidencia con otros hallazgos o a partir de conceptos teóricos, o iii) mediante la confirmación de hipótesis planteadas o sugeridas en la Introducción del artículo.

Las dos opciones se dan entre dos patrones de género encontrados en el corpus estudiado, según se ejemplifica en el análisis presentado a continuación. El primero, encontrado en (A01), es la garantía de la investigación, que presenta una serie de etapas constituidas como legitimación de los resultados, en un patrón similar al hallado en Discusiones de artículos en Microbiología (Moyano, 2014), aunque con un aumento en la inclusión de explicaciones de los resultados. El segundo, encontrado en (A02), es la justificación analítica, entendida como la argumentación a favor de una afirmación, con estructura Tesis ^ Argumentos * $\mathrm{n} \wedge$ Refuerzo de la Tesis (Martin, 1989; Martin \& Rose, 2008), tal como se halló en el trabajo con un quinto artículo dentro de esta disciplina (Moyano, 2011).

En el artículo (A01), el autor se propone aportar mayor información sobre la respuesta de dos diferentes cultivares de una misma especie forrajera (trébol 
rojo) a la defoliación o corte en la región pampeana de Argentina. Los objetivos formulados en la Introducción del artículo son los siguientes:

$>$ Evaluar el efecto de la severidad y del estado de desarrollo al momento de la defoliación sobre la acumulación de forraje y la persistencia de dos cultivares de trébol rojo de diferente ciclo vegetativo.

$>$ Relacionar estructura y tasas de rebrote de la pastura, y

$>$ Evaluar las características del sistema radical y de la acumulación de reservas en raíces. (A01)

La Discusión de (A01) retoma algunos de los resultados del estudio -probablemente los que el autor considera más relevantes-, teniendo en cuenta también variables no mencionadas en los objetivos, como la producción en diferentes épocas del año. Así, como se muestra en la Tabla 1, el texto se organiza en etapas que se determinan por cambios en el contenido ideacional, marcados por cláusulas que dan cuenta de esos resultados (negritas). Como puede observarse, en la mayoría de los casos (a excepción de la Legitimación 9), esta información funciona como hiperTema en cada etapa: se ubica en complejo clausular que inicia la etapa en el cual el autor se propone legitimar ese resultado.

La Conclusión se presenta como macroNuevo de toda la Discusión y como respuesta a cada uno de los objetivos planteados en la Introducción, de ahí que se identifiquen cuatro etapas en ella. Esas cuatro etapas están también marcadas por el cambio ideacional (negritas). Obsérvese que la Conclusión 3 se coloca en otra tipografía (negritas + cursivas), debido a que es probable que a su vez sintetice el contenido ideacional de las Conclusiones de todo el trabajo, es decir, que funcione como macroNuevo de primer nivel'1. Si este párrafo estuviera al final del texto resultaría más evidente esta lectura, que se fundamenta en el hecho de que los resultados del trabajo se presentan como prueba de la evaluación que se hace de la herramienta técnica utilizada (la defoliación) en relación con uno de los cultivares investigados. Esto se hace mediante una cláusula relacional

\footnotetext{
${ }^{1}$ Martin y Rose (2007: 197-198) muestran que en los textos pueden presentarse diferentes niveles o capas de macro e hiperTemas y macro e hiperNuevos para construir el método de desarrollo y el punto del texto, organizando la información en «ondas» mayores que pueden abarcar «ondas» menores.
} 


\begin{tabular}{|c|c|}
\hline $\begin{array}{c}\text { Legit. } \\
1\end{array}$ & $\begin{array}{l}\text { I. a densidad de ta población de tallos fue principalmente afectada por el cultivar y } \\
\text { la época del aho. Fn el primer caso ... Scheneiter y Bertin, 1998) [...]. Estacionalmente } \\
\ldots \text {...... (Bowley et al } 1988) \text {. }\end{array}$ \\
\hline $\begin{array}{l}\text { legit. } \\
2\end{array}$ & $\begin{array}{l}\text { Red presentó mayores valores de IAF que Sur, especialmente cuando la defoliación } \\
\text { se realizó en el estado de botón floral, lo cual coincide con el porte erecto y menor } \\
\text { relación hoja tallo de este último con respecto a Red (Scheneiter, 1994) }\end{array}$ \\
\hline$\underset{3}{\text { Legit. }}$ & $\begin{array}{l}\text { Las diferencias entre cultivares y la interacción cultivar por ciclo de producción en } \\
\text { la acumulación anual de forraje de trébol rojo ha sido informada previamente } \\
\text { (Scheneiter y Rosso, 2003) En términos generales... [...] }\end{array}$ \\
\hline $\begin{array}{c}\text { Legit. } \\
4\end{array}$ & $\begin{array}{l}\text { La severidad, a diferencia del estado de desarrollo, afectó marcadamente la } \\
\text { acumulación anual de forraje. De este modo, con defoliacion a } 5 \mathrm{~cm} \text { se obtuvo un } \\
\text { sustancial incremento del forraje cosechado con respecto a } 10 \mathrm{~cm} \text { de altura. Esta } \\
\text { diferencia... }\end{array}$ \\
\hline $\begin{array}{c}\text { Legit. } \\
5\end{array}$ & $\begin{array}{l}\text { En este ensayo, la defoliación en floración implicé una defoliación menos que en } \\
\text { botón floral. Esto tuvo escaso impacto ... [ ...] (De Battista y Costa, 1998, Wiersma et } \\
\text { al 1998) }\end{array}$ \\
\hline $\begin{array}{c}\text { Legit. } \\
6\end{array}$ & $\begin{array}{l}\text { Bajo el canopeo denso de primavera (en promedio se acumularon } 3,3 \text { tn } \mathrm{MS} / \mathrm{ha} \text { al } \\
\text { momento de la defoliación), hubo desprendimiento de hojas basales y pocas hojas } \\
\text { remanentes, las cuales permanecieron en un pobre ambiente luminico y con ello, } \\
\text { tuvieron menor capacidad fotosintética. En esta situacion no cabe esperar... }\end{array}$ \\
\hline Legit. & 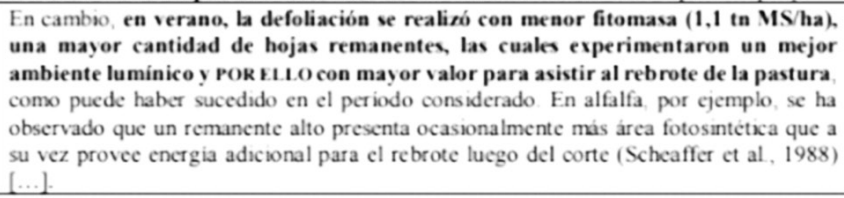 \\
\hline $\begin{array}{c}\text { Legit. } \\
\mathbf{8}\end{array}$ & 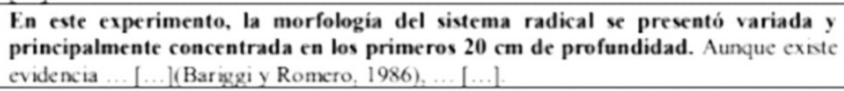 \\
\hline $\begin{array}{c}\text { Legit. } \\
9\end{array}$ & $\begin{array}{l}\text { Varios trabajos en alfalfa evidencian que . . Romero et al 1996, Collins, } 1996 \text {, } \\
\text { Heichel et al, 1988). En este experimento, la defoliación en el estado de botón floral } \\
\text { implicó dos cortes más por estación que cuando se realizó en floración sin haberse } \\
\text { observado por ello un menor porcentaje de CTNE al final del ciclo. Por el contrario, } \\
\text { el efecto de la severidad coincide con las referencias previas ya que la alta severidad } \\
\text { de defoliación implicó menor concentración de CTNE en Sur al final del primer } \\
\text { invierno y en Red al final del segundo. }\end{array}$ \\
\hline $\begin{array}{c}\text { legit. } \\
10\end{array}$ & $\begin{array}{l}\text { Sin embargo, la diferencia más notable en la concentración de CTNE se obtuvo por } \\
\text { efecte del cultivar al final del primer otono. No existen muchas evidencias de tales } \\
\text { diferencias [...] }\end{array}$ \\
\hline $\begin{array}{c}\text { Concl. } \\
1\end{array}$ & $\begin{array}{l}\text { La acumulación de fitomasa tanto de la parte aérea como de las raices fue afectada } \\
\text { por la altura de defoliación y el germoplasma. En el primer caso, la cosecha anual de } \\
\text { forraje fue mayor con defoliación a } 5 \mathrm{~cm} \text { de altura mientras la masa de raices resultó más } \\
\text { elevada con defoliacón a } 10 \mathrm{~cm} \text { Con respecto al germoplasma, en el primer ciclo, el } \\
\text { cultivar El Sureño INTA acumub más fitomasa aérea y menos de raices que el cultivar } \\
\text { Redland II. }\end{array}$ \\
\hline $\begin{array}{c}\text { Concl. } \\
2\end{array}$ & $\begin{array}{l}\text { Ia tasa de acumulación de forraje se relacionó ocasional y débilmente con variables } \\
\text { estructurales de la pastura. De este modo, en verano el área foliar remanente explicó } \\
\text { en parte la tas de acumulación de forraje mentras que en primavera no se detectó } \\
\text { relación significativa alguna. }\end{array}$ \\
\hline $\begin{array}{c}\text { Concl. } \\
3\end{array}$ & $\begin{array}{l}\text { Los resultados obtenidos muestran que, en un material genético con acasa } \\
\text { persistencia vegetativa como el cultivar El Sureño INTA, el manejo de la defoliación } \\
\text { no parece ser una alternativa para mejorar cte aspecto. }\end{array}$ \\
\hline $\begin{array}{c}\text { Concl. } \\
4\end{array}$ & $\begin{array}{l}\text { I a concentración de carbohidratos no estructurales fue a fectada per el cultivar y, } \\
\text { en menor medida, por el manejo de la defoliación. El cv Redland II tiene con respecto } \\
\text { al cv. EI Sureno INTA, mayor capacidad para almacenar reservas en raices. lo cual puede } \\
\text { contribuir a su persistencia en el norte de la provincia de Buenos Aires. }\end{array}$ \\
\hline
\end{tabular}

Tabla 1. Garantía de la investigación en (A03). 
identificadora (1) (proceso en negrita + subrayado), en la que los resultados funcionan como Símbolo (negritas) y la cláusula incrustada que los interpreta funciona como Valor ${ }^{2}$ (cursiva) (Halliday, 1993; Halliday \& Matthiessen, 2004). La evaluación de la defoliación aplicada al cultivar El Sureño INTA se evoca mediante la negación del atributo a través del proceso (subrayado).

(1) Los resultados obtenidos muestran [[que, en un material genético con escasa persistencia vegetativa como el cultivar El Sureño INTA, el manejo de la defoliación no parece ser una alternativa para [[mejorar este aspecto]] ]]./II

El género por el que el autor opta en este caso es la garantía de la investigación, que presenta, como variante en relación con Discusiones en Microbiología (Moyano, 2014), un uso mayor de la explicación. En efecto, en la mayoría de las etapas se presentan los resultados a fin de explicar sus causas, haciendo referencia a coincidencias o diferencias con los resultados obtenidos por otros autores en ensayos con la misma u otras especies. De esta manera, la legitimación de resultados se hace no solo a través de la coincidencia con otros autores, sino fundamentalmente de su explicación, como puede observarse en Legitimación 1, por ejemplo (2).

(2) La densidad de la población de tallos fue principalmente afectada por el cultivar y la época del año.///

En el primer caso, la mayor densidad de tallos en primavera, de un cultivar de floración intermedia como Red [[comparado con uno de ciclo vegetativo más precoz como Sur]], puede estar relacionada con su respuesta más tardía al estímulo del fotoperiódico (Jones, 1974);// a su vez, en verano se ha observado previamente una menor pérdida de plantas de Red con respecto a Sur (Scheneiter y Bertín, 1998),// lo cual puede implicar para el primero una mayor densidad de tallos en marzo.///

Estacionalmente, el hecho más notable fue la escasa densidad de tallos en el verano con respecto a la primavera,// lo cual sugeriría [lque esta variable, y no el crecimiento por tallo individual es la que limita el rebrote del trébol rojo en el período estival (Bowley et al., 1988)]].///

\footnotetext{
2 Las traducciones de las funciones léxico-gramaticales utilizadas en este trabajo están tomadas de Ghio y Fernández (2008)
} 
Esta etapa se inicia con un hiperTema (negrita + cursiva con menor margen), que anuncia los resultados que van a ser explicados. Luego, dos Temas marcados (negrita + cursiva + subrayado) señalan la distribución de la información en lo que resta del párrafo: en primer lugar (primera fase), la incidencia del cultivar en la densidad de población de tallos; en segundo lugar (segunda fase), la de la época del año. La explicación de cada aspecto de estos resultados se presenta a través de diferentes recursos. En la primera fase, se utilizan grupos verbales para establecer la relación causal, en ambos casos modalizada (negrita + cursiva). En la segunda, se usa un complejo clausular que presenta, en primer lugar, el resultado que se explica (negritas). Este contenido ideacional se retoma mediante el pronombre «lo cual» (subrayado) que funciona como Símbolo en una cláusula relacional identificadora (proceso en negrita + subrayado) (Halliday, 1993; Halliday \& Matthiessen, 2004). La cláusula incrustada que funciona como Valor (cursiva) establece la explicación que el autor propone. La causa también está modalizada, tanto por el verbo elegido (sugerir, versus, por ejemplo, demostrar), que gradúa el valor probatorio del Símbolo, como por el uso del condicional (sugeriría). Los resultados hallados y su explicación se legitiman también mediante referencias a trabajos de otros autores, en todos los casos presentados como citas no integradas.

El principal recurso para la explicación de resultados en el texto analizado son las conexiones lógicas (Martin \& Rose, 2007), realizadas mediante conjunciones (versales + negrita) (3) y (5), y, especialmente, a través de metáforas lógicas (Martin \& Rose, 2007: 148-152). Estas consisten en la realización de las relaciones lógicas a través de procesos realizados como grupos verbales (negrita + cursiva) (4) o de sustantivos en grupos nominales (negrita + subrayado) (5). Finalmente, la relación causal puede expresarse a través de cláusulas dependientes (subrayado doble) en relación de ampliación con la independiente (6). Si bien en este ejemplo la conexión entre cláusulas se establece mediante lo que en principio puede interpretarse como una relación temporal, el estado de la pastura en la estación del año señalada se propone como causa para la diferencia obtenida como resultado ${ }^{3}$.

\footnotetext{
${ }^{3}$ El contexto de uso (cf. Legitimación 4 en la Tabla 1) es lo que habilita la interpretación causal para la relación entre las cláusulas dependientes y la independiente.
} 
(3) En cambio, en verano, la defoliación se realizó con menor fitomasa (1,1 tnMS/ha), una mayor cantidad de hojas remanentes, [[las cuales experimentaron un mejor ambiente lumínico y POR ELLO con mayor valor [[para asistir al rebrote de la pastura]],// como puede haber sucedido en el período considerado]].///

(4) Esta menor capacidad de Sur con respecto a Red para asignar asimilatos hacia raíces y corona podría explicar en parte la escasa persistencia del primero.

(5) Esto tuvo escaso impacto en la acumulación anual de forraje, DESDE QUE se ha comprobado que un número menor de cortes por año da lugar a una mayor acumulación anual de forraje en trébol rojo (De Battista y Costa, 1998; Wiersma et al., 1998). ${ }^{4}$ (6) Esta diferencia fue obtenida en la primera parte de la primavera,// cuando comenzó la defoliación diferencial// y cuando la pastura revirtió al estado de roseta.///

Como ya se señaló en el análisis de la Legitimación 1 (2), estas explicaciones se sustentan en las referencias a otros trabajos o a conceptos teóricos. De esta manera, los datos y su explicación se hallan legitimados por otros hallazgos en el campo disciplinar. Obsérvese (7), sin embargo, que en Legitimación 8, por ejemplo, la relación causal se ve negada (negrita + cursiva), en oposición a la bibliografía referenciada introducida mediante concesión (negrita + cursiva + subrayado), sin que se explique esta diferencia. Desde la perspectiva interpersonal, se observa nuevamente que esta oposición se presenta como un par de concesión más contraexpectativa.

(7) [CONCESIÓN] Aunque existe evidencia que un residuo alto luego de un corte contribuye al incremento del peso en las raíces en alfalfa, lo cual favorece la persistencia de la especie (Bariggi y Romero, 1986), [CONTRAEXPECTATIVA] la defoliación a $10 \mathrm{~cm}$ de altura no implicó mayor cobertura a los 39 meses del experimento, ni mayor densidad de tallos en el cultivar Sur y sólo una tendencia $(p<0,1)$ a una mayor densidad en Red en marzo de 2001.

\footnotetext{
${ }^{4}$ En este texto, «desde que» puede leerse como «dado que», locución conjuntiva causal. Cf. el mismo uso en Legitimación 10.
} 
Así, el trabajo aporta a la obtención de datos sobre el comportamiento de la especie en observación en una región determinada, datos que permitirán, posteriormente, avanzar sobre generalizaciones que fundamenten decisiones para su manejo. No hay hipótesis ni razonamiento, sino tal como se anuncia en los objetivos formulados en la Introducción, acumulación de información sobre el comportamiento de esta especie como efecto de las condiciones evaluadas y la comparación entre dos cultivares, para señalar las ventajas de uno sobre otro. Esto se ve confirmado por las Conclusiones, que, como ya se señaló, se organizan como respuesta a los objetivos del trabajo, presentando una síntesis de la información obtenida, destacando las variables que incidieron en los resultados mediante relaciones causales (negritas + subrayado) y las comparaciones entre cultivares (negrita + cursiva), como se ejemplifica mediante el último párrafo del artículo (8).

(8) La concentración de carbohidratos no estructurales fue afectada por el cultivar y, en menor medida, por el manejo de la defoliación./// El cv. Redland II tiene con respecto al cv. El Sureño INTA, mayor capacidad para [[almacenar reservas en raíces]],// lo cual puede contribuir a su persistencia en el norte de la provincia de Buenos Aires.///

A fin de ejemplificar la co-articulación del uso de los recursos discursivos en las explicaciones, se tomará la Legitimación 5 (9). Esta consiste en la explicación de resultados basada en hallazgos de otros autores, introducidos como proyección de hechos (subrayado) en la que la referencia a los autores citados se coloca como cita no integrada (negritas). Estos hallazgos aparecen en relación de causa interna con los resultados del ensayo a través de una conjunción (versales negritas). Así, la información producida por otros autores aparece como argumento para sostener lo dicho sobre lo obtenido en el ensayo. Estos resultados, a su vez, son planteados como consecuencia externa de una herramienta técnica mediante un proceso (implicó) y un atributo graduado (escaso impacto): se trata del efecto de la defoliación en la cantidad de cortes según el estado de maduración de la planta y el de esto sobre la acumulación de forraje. 
(9) En este ensayo, la defoliación en floración implicó una defoliación menos que en botón floral./// Esto tuvo escaso impacto en la acumulación anual de forraje,// DESDE QUE se ha comprobado [[que un número menor de cortes por año da lugar a una mayor acumulación anual de forraje en trébol rojo (De Battista y Costa, 1998; Wiersma et al., 1998)]].///

La Legitimación 6 y la 7 se basan en un elemento teórico ampliamente establecido (el concepto de fotosíntesis) (10). En versales + negrita se marcan los Adjuntos que funcionan como conjunción causal (causa externa), mientras en negrita + subrayado una metáfora lógica que construye negación de la causa modalizada (negrita + cursiva). Esta modalización de procesos que realizan relaciones lógicas permiten graduar la relación, considerándola más o menos posible, recurso que resulta central para el discurso científico para indicar si hay o no suficiente evidencia para sostenerla. De esta manera, la metáfora lógica se orienta al compromiso con el lector (Martin \& Rose, 2007).

(10) [Legitimación 6] Bajo el canopeo denso de primavera (en promedio se acumularon 3,3 tn MS/ha al momento de la defoliación), hubo desprendimiento de hojas basales y pocas hojas remanentes, [[las cuales permanecieron en un pobre ambiente lumínico// y, CON ELLO, tuvieron menor capacidad fotosintética]]./// En esta situación no cabe esperar relación alguna entre la tasa de acumulación y el área foliar remanente,// como se observó en el presente experimento./// [Legitimación 7] En cambio en verano, la defoliación se realizó con menor fitomasa (1,1 tnMS/ha), una mayor cantidad de hojas remanentes, [[las cuales experimentaron un mejor ambiente lumínico// y POR ELLo, con mayor valor para asistir al rebrote de la pastura,// como puede haber sucedido en el período considerado]]./// [...]

En algunos casos, como puede observarse en (11), la explicación de los resultados se plantea modalizada como posible cuando no hay coincidencia con los resultados de otros estudios, aspecto que se marca mediante negación de la información ideacional (subrayado). En negrita + subrayado se marcan las relaciones causales modalizadas: la primera realizada mediante un atributo (posible) de la cláusula incrustada que plantea la explicación; la segunda mediante un 
proceso relacional causal modalizado (Halliday, (1993). En versales + negrita se marcan nominalizaciones de la relación causal (efecto; otras causas). La segunda (otras causas) se elabora luego de la recomendación de evaluación, brindando un ejemplo a falta de información bibliográfica que sostenga la explicación del resultado (subrayado doble).

(11) Sin embargo, la diferencia más notable en la concentración de CTNE se obtuvo por EfEcto del cultivar al final del primer otoño./// No existen muchas evidencias de tales diferencias entre distintos germoplasmas./// Desde que, al final del primer año, Sur tuvo con respecto a Red mayor acumulación de biomasa aérea y menor persistencia,// es posible [ [que el primero destine más recursos en la elongación de tallos y estructuras reproductivas durante la primavera y el verano// lo cual puede determinar un menor destino de asimilatos hacia otros destinos de la planta (raíces, reservas)./// Esta menor capacidad de Sur con respecto a Red para [[asignar asimilatos hacia raíces y corona]] podría explicar en parte la escasa persistencia del primero./// No obstante, OTRAS CAUSAS deberían ser evaluadas, como la diferencia en el comportamiento sanitario entre los cultivares en enfermedades [[que condicionan la persistencia del trébol rojo en el norte de la Pcia de Buenos Aires] $]$.///

Estos ejemplos permiten sostener que, más allá de que el autor, como investigador, procura explicar los resultados encontrados, lo hace buscando, en lo posible, su legitimación mediante algún tipo de coincidencia con los hallazgos en otros estudios o a través del uso de conceptos teóricos aceptados en la disciplina: la construcción de conocimento en la disciplina parece realizarse por integración (Bernstein, 1999).

Los recursos semántico-discursivos más relevantes en este género son la PERIODICIDAD, la CONJUNCIÓN, particularmente en el uso de metáforas lógicas, y la VALORACIÓN, especialmente recursos del subsistema de COMPROMISO. Estos recursos permiten ordenar el flujo de información, explicar los resultados e incorporar voces de otros investigadores para establecer diálogo con la comunidad disciplinar destinataria.

El artículo que consideramos a continuación (A02) se inscribe abiertamente en una cuestión polémica en el marco de la disciplina. Según afirma el autor en la 
Introducción, el uso de la inoculación bacteriana en los procesos de fermentación durante el ensilaje de materiales forrajeros es cuestionada por productores y por otros investigadores por no ser estrictamente necesaria:

... la utilización de inoculantes bacterianos es aun escasa y frecuentemente discutida tanto por técnicos y productores usuarios de estos productos, como en la literatura especializada (Muck y Kung, 1997). (A02)

A pesar de ello, el artículo se propone como objetivo analizar nuevamente los efectos de su aplicación en silos de maíz y sorgo a fin de evaluar sus resultados así como los criterios para decidir la conveniencia de su uso:

El objetivo de este trabajo fue analizar los efectos de la aplicación de un inoculante bacteriano sobre la calidad de silajes de maíz y sorgo en la región húmeda de Argentina y discutir los criterios sobre los cuales decidir la conveniencia de su aplicación. (A02)

Si bien no se plantean hipótesis en la Introducción de (A02), el planteo de los objetivos, que contradice la información generada ya en el campo, construye como expectativa del texto la defensa de la herramienta tecnológica en cuestión, la inoculación bacteriana en silos de maíz y sorgo. En consecuencia, la Discusión se propone como una justificación analítica, aunque en esta oportunidad el autor incluye al inicio dos textos adicionales (Tabla 2), como géneros que se articulan con ella para contribuir a su propósito global en un macrogénero.

El primero de esos textos es, en términos de género, un informe de evaluación de los materiales introducidos en los silos, que establece el punto de partida para el análisis de los resultados por comparación con las características de los materiales al finalizar el proceso. El segundo, un informe de evaluación de los resultados del ensayo, cuya primera fase presenta la metodología utilizada para esa evaluación. 


\begin{tabular}{|c|c|}
\hline $\begin{array}{l}\text { Informe de } \\
\text { evaluación } \\
\text { de } \\
\text { materiales } \\
\text { originales }\end{array}$ & $\begin{array}{l}\text { Los materiales originales presentaron en varios casos un contenido de materia seca } \\
\text { inferior al óptimo deseable para ensilar estos cultivos, pero los contenidos de FDA y } \\
\text { PB se ubicaron dentro del rango usualmente hallado en este tipo de alimentos (Jaurena } \\
\text { y Danelón, 2001). La concentración de los carbohidratos solubles de los silajes de } \\
\text { planta entera de maiz disminuyó en función del avance del estado fenológico, tal } \\
\text { como es esperable (McDonald et al., 1991) [...] }\end{array}$ \\
\hline $\begin{array}{l}\text { Informe de } \\
\text { evaluación } \\
\text { de } \\
\text { resultados }\end{array}$ & \\
\hline $\begin{array}{l}\text { Método de } \\
\text { análisis }\end{array}$ & $\begin{array}{l}\text { La evaluación del proceso de ensilaje involucra aspectos relacionados con la } \\
\text { conservación del material original y con el valor nutritivo del ensilado para el ganado. } \\
\text { La eficiencia del proceso puede juzgarse en forma directa }[\ldots] \text { o suele inferirse } \\
\text { indirectamente }[\ldots]\end{array}$ \\
\hline $\begin{array}{l}\text { Evaluación } \\
\text { de } \\
\text { Resultados }\end{array}$ & $\begin{array}{l}\text { Los indicadores de la recuperación de la MS fueron muy buenos (no difirieron } \\
\text { estadisticamente del } 100 \% \text { en ningún caso) y los pesos especificos logrados para } \\
\text { ambos cultivos se ubicaron dentro del rango deseado y comúnmente aceptado como } \\
\text { promedio de ensilajes comerciales. Solo se detectaron diferencias asociadas al cultivo } \\
{[\ldots]} \\
\text { El perfil fermentativo de todos los silajes obtenidos para ambas especies y } \\
\text { tratamientos puede calificarse como muy bueno en virtud de los valores de ... }\end{array}$ \\
\hline
\end{tabular}

Tabla 2. Informes de evaluación de materiales originales y de producto del ensilaje (A02)

A través de esta primera parte del texto, se responde al primer objetivo del trabajo, que consiste en comparar los resultados de la conservación de materiales inoculados y sin inocular para sopesar las diferencias entre tratamientos. Tal como se esperaba según lo planteado en la Introducción, los diferentes tratamientos arrojan resultados sin diferencias estadísticamente significativas, lo que justificaría la posición general que considera innecesaria la aplicación de inoculantes bacterianos para mejorar la conservación de forraje ensilado. Estos resultados, entonces, se incluyen en los obtenidos antes en la disciplina, lo que, como ya se ha señalado para otros textos, legitima los resultados obtenidos en el trabajo.

Para lograr este propósito, en el primer informe se co-articulan diferentes recursos (12): el estado de los materiales al ingresar a los silos se evalúa por comparación con otros resultados, lo que puede apreciarse ideacionalmente (negritas + subrayado) a través de adjetivos comparativos (inferior) o de construcciones comparativas ( $t a l$ como), de circunstancias que permiten construir la comparación (dentro del rango...) o de un proceso material que contribuye a la comparación de valores numéricos no expresados (disminuyó). Estos recursos se 
complementan con otros interpersonales, como la apreciación graduada (inferior al óptimo) (negrita + cursiva) y, por otro lado, la proyección metafórica (Moyano, 2015b), realizada a través de un participio (subrayado), como atribución a otros trabajos, referenciados mediante cita no integrada (negrita). En definitiva, como se muestra en este fragmento tomado como ejemplo, los materiales introducidos al silo son materiales de tipo estándar (dentro del rango usualmente hallado, tal como es esperable), de acuerdo con los logrados tanto en la práctica profesional como en la bibliografía e, incluso, no tan buenos como podrían haberlo sido.

(12) Los materiales originales presentaron en varios casos un contenido de materia seca inferior al óptimo deseable para ensilar estos cultivos,// pero los contenidos de FDA y PB se ubicaron dentro del rango [ [usualmente hallado en este tipo de alimentos (Jaurena y Danelón, 2001)]]./// La concentración de los carbohidratos solubles de los silajes de planta entera de maíz disminuyó en función del avance del estado fenológico,// tal como es esperable (McDonald et al., 1991) [...]///

En el segundo informe (13), se evalúa mediante apreciación graduada (negrita + cursiva) el producto del ensilaje, tanto en los materiales inoculados como en los casos testigo - los no inoculados - lo que se evidencia a través del uso de la graduación (fuerza: cantidad) (negrita + subrayado). Los parámetros para la evaluación son las variables mencionadas (subrayado), cuyos valores no se consignan en la Discusión sino en Resultados y no parecen ser motivo de objeción por parte de los lectores, ya que no se hace referencia a otros autores, lo que implica que son datos aceptables, ya establecidos en la disciplina. La modalización del verbo (versales), sin embargo, abre el reconocimiento de la existencia de otras alternativas posibles.

(13) El perfil fermentativo de todos los silajes obtenidos para ambas especies y tratamientos PUEDE CALIFICARSE como muy bueno en virtud de los valores de $\mathrm{pH}$, $\underline{\mathrm{N}-\mathrm{NH} 3 / \mathrm{N} \text { total (NT), proporción de láctico respecto a los AGT y relación láctico/acético. }}$ 
Otras evaluaciones de los resultados (14) se hacen mediante apreciación (negritas + cursiva) basada en los datos estadísticos correspondientes a la comparación del material original y el procesado presentados como prueba para la valoración (negritas + subrayado), o con los mismos recursos de comparación (negritas) y de atribución ya utilizados en el informe anterior (subrayados). Los resultados del ensilaje obtenidos en el ensayo quedan, entonces, legitimados dentro de la disciplina como esperables.

(14) Los indicadores de la recuperación de la MS fueron muy buenos (no difirieron estadísticamente del $100 \%$ en ningún caso)// y los pesos específicos [[logrados para ambos cultivos]] se ubicaron dentro del rango [[deseado// y comúnmente aceptado como promedio de ensilajes comerciales]].///

Sin embargo, inmediatamente a continuación (15) el autor plantea, mediante contraexpectativa (versales + negritas), una afirmación que propone una novedad con respecto a lo que se viene sosteniendo en coincidencia con otros resultados en el mismo campo, ya sea dentro de la disciplina o de la práctica productiva o comercial. Es esta aseveración la que se constituye en la Tesis de la justificación que se desarrolla a partir de allí, según se observa en la Tabla 3, y mediante la cual se defiende, como se señaló antes, el uso de inoculantes para silos de sorgo y maíz y se proponen los criterios para discutir la conveniencia de su aplicación, como se anuncia en el segundo objetivo del trabajo. Para ello, el autor se basa, nuevamente, en los resultados obtenidos y en la referencia a otros autores. Obsérvese en la Tabla 3 que el Argumento 1 se encuentra distribuido en dos momentos del texto.

(15) NO OBSTANTE LO ANTERIOR, ambos cultivos mostraron respuestas positivas a la inoculación. 


\begin{tabular}{|l|l|}
\hline Tesis & $\begin{array}{l}\text { No obstante lo anterior, ambos cultivos mostraron respuestas positivas a la } \\
\text { inoculación. }\end{array}$ \\
\hline Arg 1 & $\begin{array}{l}\text { En el caso de los silajes de planta entera de maíz se observaron diferencias a favor de } \\
\begin{array}{l}\text { los materiales inoculados, dado que si bien la producción total de ácidos y de AL no } \\
\text { cambió, sí se registró un menor contenido de ácido acético }[\ldots] \text { Estos resultados } \\
\text { sugieren... [...] (Wooldford, 1984...). La mayor relación }[\ldots] \text { también indica... }[\ldots]\end{array}\end{array}$ \\
\hline Arg 2 & $\begin{array}{l}\text { En el caso de los silajes de sorgo, }[\ldots] \text { a pesar de }[\ldots] \text { los materiales que fueron } \\
\text { inoculados lograron Ph plenamente satisfactorios... [...] Los resultados sugieren que.... }\end{array}$ \\
\hline Arg 1 & $\begin{array}{l}\text { En el caso del silaje de planta entera de maiz la inoculación induciria una } \\
\text { fermentación más rápida mejorando ligeramente las caracteristicas fermentativas del } \\
\text { ensilado. }\end{array}$ \\
\hline Arg 3 & $\begin{array}{l}\text { Más allá de estos resultados y reconociendo la importancia de .... el uso de } \\
\text { inoculantes bacterianos puede resultar en mejoras sobre la producción animal (Cleale et } \\
\text { al, 1990). [...] }\end{array}$ \\
\hline
\end{tabular}

Tabla 3. Justificación analítica en (A02)

Desde la perspectiva de la PERIODICIDAD, la Tesis funciona como macroTema de la justificación, anunciando los resultados, que se consideran respuestas positivas a la inoculación, y que serán analizados en los Argumentos 1 y 2, negociando con la audiencia su interpretación. La introducción de estos Argumentos está señalada por Temas marcados que refieren a los cultivos mencionados en la Tesis (ambos cultivos). El tercer Argumento también se introduce mediante un Tema marcado, que anuncia un avance hacia otro aspecto, como los efectos de la aplicación del inoculante en la producción animal y el consumo. De esta manera, el autor responde al segundo objetivo del trabajo, la discusión de criterios para la decisión de la aplicación del inoculante.

Los recursos de VALORACIÓN utilizados en el primer Argumento (16) para la negociación con los lectores y las posiciones citadas en la Introducción son varios y se articulan de manera compleja. En primer lugar, se propone una lectura de los resultados coincidente con la anunciada en la Tesis para uno de los cultivos, como una aserción categórica (negrita+subrayado), para la que, inmediatamente, se aporta un argumento basado en los datos. Esto se realiza mediante una conjunción interna (versales negritas) (dado que). Asimismo, la conjunción introduce un par de concesión más contraexpectativa, a fin de persuadir acerca de la lectura propuesta sobre la base de datos hallados en el ensayo que se legitiman mediante la comparación con los obtenidos en otro estudio, introducidos por proyección (subrayado). Por otro lado, estos datos se proponen como prueba para dos infe- 
rencias (negrita + cursiva), realizadas en cláusulas relacionales identificadoras a través del uso de procesos relacionales identificadores (sugerir, indicar) (Halliday, 1993); Halliday \& Matthiessen, 2004), como opción de proclamación en la VALORACIÓN (pronunciarse). Una de estas inferencias, además, está sostenida por dos citas no integradas (negritas). Así, si bien el autor admite otras posiciones frente a la suya introduciendo concesiones, argumenta para persuadir al lector de su explicación de la relación entre los datos obtenidos.

(16) En el caso de los silajes de planta entera de maíz se observaron diferencias a favor de los materiales inoculados,// DADO QUE [CONCESIÓN] <<si bien la producción total de ácidos y de AL no cambió >>, [CONTRAEXPECTATIVA] sí se registró un menor contenido de ácido acético,// aumentando consecuentemente la proporción de $\mathrm{AL}$ y la relación láctico/acético./// Estos cambios disminuyeron también el pH de estabilización y la relación $\mathrm{N}-\mathrm{NH}_{3} / \mathrm{NT}$ en modo similar a los resultados [[reportados por Lindgren y Peterson (1990)]]./// Estos resultados sugieren un menor desarrollo de enterobacterias y extensión de los procesos de proteólisis y deaminación típicos de las fases iniciales del ensilaje (Woolford, 1984; Henderson, 1993)./// La mayor relación láctico/acético también indica una utilización más eficiente de los azúcares disponibles en el cultivo original hacia la síntesis de ácido láctico,// [CONCESIÓN] pese a que dicha diferencia no fuera detectada en los indicadores de recuperación de MS// sin duda debido a la falta de precisión de la técnica [[empleada]].///

Este primer argumento se cierra más adelante en el texto (17), mediante lo que podría considerarse una conclusión del razonamiento, donde se presenta el efecto de la inoculación sobre el silo de maíz mediante una metáfora lógica, la causa realizada mediante un proceso y modalizada a través del verbo en condicional (negritas + cursiva + subrayado).

(66) En el caso del silaje de planta entera de maíz, la inoculación induciría una fermentación más rápida mejorando ligeramente las características fermentativas del ensilado.

Como puede observarse mediante este conjunto de recursos, el autor, si bien reconoce la posición contraria a la que defiende, contrae todo lo posible las po- 
sibilidades de interpretación de los datos obtenidos. Sin embargo, deja abierta la interpretación final mediante el uso de modalización expresada a través del condicional (17), como a la espera de más evidencias para sostenerla.

Sin referencias a otros autores, en el segundo Argumento (18) el autor utiliza un par de concesión más contraexpectativa para sostener la utilidad del recurso tecnológico (la inoculación bacteriana) que el texto defiende (proclamar:pronunciarse). En la contraexpectativa, se presenta el contraste entre los materiales iniciales y los inoculados, a través de recursos de graduación (negritas) aplicados a contenidos ideacionales (cursivas) o, en un caso, a una apreciación (negrita + cursiva + subrayado). Cabe señalar que la graduación, como recurso discursivo, se realiza mediante una variedad de clases de palabras: adjetivos, adverbios o verbos. El último complejo clausular del fragmento construye una inferencia a partir de los datos. Los resultados se construyen como Símbolo en una cláusula relacional identificadora (Halliday, 1993); Halliday \& Matthiessen, 2004), que propone como Valor (negrita + cursiva) una confirmación de la Tesis. Esta relación de causa interna entre los resultados y su interpretación se presenta graduada $^{5}$ (subrayado), contemplando la posibilidad de otras interpretaciones, lo que reduce, en alguna medida, la fuerza de la proclamación.

(18) En el caso de los silajes de sorgo, el 22\% (2/9) de los minisilos o [[inoculados]] tuvieron pH muy altos [[asociados a problemas con las fermentaciones]]./// Cabe señalar [[que [CONCESIÓN] a pesar de los relativamente bajos contenidos de CSol iniciales,// [CONTRAEXPECTATIVA] los materiales [[que fueron inoculados]] lograron $\mathrm{pH}$ plenamente satisfactorios $(3,8$ y 3,9) con producciones de AGT [[que prácticamente duplicaron los valores de los controles// y aumentando la proporción de láctico// y reduciendo la participación del ácido acético entre los productos finales]] ]]./// Los resultados sugieren [[que en sorgos con bajos contenidos de carbohidratos solubles, la inoculación con BAL aumentaría las probabilidades de obtener silajes con buenas características fermentativas]].///

${ }^{5}$ La graduación consiste en el uso de un verbo como «sugerir» en lugar de «mostrar» o «demostrar». 
El tercer Argumento, finalmente, se relaciona con la evaluación de los criterios adicionales para decidir la conveniencia de la aplicación de inoculantes (19). Luego de una concesión, la relación causal entre el uso de inoculantes y la mejora sobre la producción animal aparece modalizada (negritas + cursiva), pero se sostiene mediante su atribución a una fuente que se introduce como cita no integrada (negritas). Asimismo, para el cierre de la Discusión, el investigador introduce una cita a través del uso de proyección (subrayado), que puede interpretarse, a causa del verbo utilizado, como restricción de posiciones alternativas (refrendar), es decir, como contracción dialógica, lo que permite sostener fuertemente la posición defendida.

(19) ... hay situaciones [[en las que [CONCESIÓN] << aun habiendo pocas mejoras en las características de fermentación $>>$, [CONTRAEXPECTATIVA] el uso de inoculantes bacterianos puede resultar en mejoras sobre la producción animal (Cleale et al, 1990)]]./// Henderson (1993) sostiene// que los primeros estadios de la fermentación y el efecto de los aditivos en esta etapa generarían características (aun no identificadas) [[que promoverían la productividad animal y el consumo voluntario]].///

Finalmente, en el capítulo reservado para las Conclusiones, se presenta una síntesis esquemática del artículo que repite la estructura argumentativa en una justificación analítica: desde la perspectiva textual, entonces, resulta un macroNuevo para el artículo. En primer lugar, se plantea nuevamente la cuestión polémica, y si bien se deja implícita la Tesis (repuesta entre corchetes], a continuación, se hace una evaluación de los resultados como Argumentos y se termina con la propuesta de Recomendaciones para investigaciones futuras que confirmarían la posición adoptada y los criterios de decisión, como paso adicional del género, frecuente en los artículos de investigación (Tabla 4). 


\begin{tabular}{|l|l|}
\hline \multicolumn{1}{|c|}{$\begin{array}{c}\text { Cuestión } \\
\text { polémica }\end{array}$} & $\begin{array}{l}\text { Frecuentemente se discute la importancia de aplicar inoculantes bacterianos a los } \\
\text { silajes de maiz y sorgo debido al escaso efecto observado en términos de pH de } \\
\text { estabilización y concentración de } \mathrm{NH}_{3} .\end{array}$ \\
\hline $\begin{array}{l}\text { [Tesis } \\
\text { implícita] }\end{array}$ & $\begin{array}{l}\text { [Sin embargo, los resultados de este trabajo sugieren que la aplicación de BAL } \\
\text { es recomendable para cultivos de sorgo y de maiz] }\end{array}$ \\
\hline Arg 1 & $\begin{array}{l}\text { La aplicación de BAL en cultivos de sorgo mostraron efectos positivos, } \\
\text { mostrando que se reduciria el riesgo de fermentaciones indeseables. }\end{array}$ \\
\hline Arg 2 & $\begin{array}{l}\text { En el caso del silaje de planta entera de maiz, los resultados en general pueden } \\
\text { asumirse como satisfactorios independientemente de la aplicación de BAL, pero } \\
\text { hubo evidencias de que su aplicación mejoró el curso de la fermentación. }\end{array}$ \\
\hline $\begin{array}{l}\text { Recomenda- } \\
\text { ción }\end{array}$ & $\begin{array}{l}\text { Estudios complementarios con monitoreo de las pérdidas de materia seca durante } \\
\text { el ensilado y periodo postapertura, junto con el impacto de la inoculación sobre } \\
\text { el consumo voluntario serian deseables para efectuar un análisis completo de los } \\
\text { beneficios de los inoculantes bacterianos. }\end{array}$ \\
\hline
\end{tabular}

Tabla 4. Estructura de la sección Conclusiones de (A02)

Como se observó en el análisis, la Discusión de (A02) se constituye en un macrogénero. Los dos primeros informes preparan la justificación analítica que se propone defender la herramienta técnica propuesta, en oposición a otras voces que asumen la posición contraria. Sin embargo, el autor utiliza los dos informes para ubicar los resultados de su estudio en el marco de las proposiciones ya efectuadas en la disciplina, a fin de legitimarlos. No obstante eso, el resto de la Discusión tiene por finalidad defender una posición alternativa, de manera que los recursos de la VALORACIÓN adquieren mayor relevancia que en (A01) y el otro texto del corpus que se configura como garantía de resultados. En el cuarto texto, que también instancia una justificación, se dan recursos de VALORACIÓN similares.

\section{REFLEXIONES FINALES}

En este trabajo se da cuenta del análisis de la sección Discusión de artículos de Ciencias agrarias, a partir de un corpus de cuatro textos, de los cuales solo se presentan dos, no solo por razones de espacio sino porque estos representan los dos patrones encontrados.

En efecto, se ha podido mostrar que no hay un único patrón para la construcción de esta sección en esta disciplina, sino que los géneros elegidos para cerrar 
los artículos de investigación son al menos dos. En primer lugar, se identificó la garantía de la investigación, en un patrón similar al hallado en Microbiología (Moyano, 2014). Así, pueden encontrarse artículos en los que el propósito global de la Discusión es, precisamente, dar garantías de que los resultados obtenidos pueden ser incluidos en el cuerpo de la disciplina dado que, o se encuentran entre los parámetros esperables o es posible explicar las diferencias con ellos. El género encontrado se denomina garantía de resultados, tal como el que se encontró en Microbiología, y se constituye por una serie de etapas denominadas Legitimación de los resultados, seguidas de Conclusiones o Recomendaciones. En algunos casos, en las etapas Legitimación en esta disciplina se pone el énfasis en la explicación de resultados, lograda de dos maneras: a partir de lo establecido por otros autores como resultados empíricos que pueden relacionarse con los obtenidos en el propio trabajo o a partir de conceptos teóricos. De esta manera, las explicaciones de resultados también tienen como propósito legitimar los resultados obtenidos. Finalmente, cuando se trata de artículos que presentan hipótesis explícitas o implícitas en la Introducción, el género elegido para la Discusión tiende a ser la justificación analítica, constituida por una Tesis y $\mathrm{n}$ Argumentos, con un Refuerzo de la Tesis que aparece como no obligatorio. Este género puede presentarse también combinado con otros en un macrogénero. El propósito de esta opción es persuadir al lector acerca de los beneficios de una herramienta tecnológica determinada para finalidades productivas específicas en regiones geográficas también específicas.

Cabe señalar que en todos los casos analizados, a veces bajo un subtítulo «Conclusiones» o «Consideraciones Finales» o como último párrafo de la sección titulada «Discusión», los artículos se cierran con un macroNuevo, dando respuesta a los objetivos del trabajo. Asimismo, en el caso de las justificaciones, confirman las hipótesis. 


\section{REFERENCIAS BIBLIOGRÁFICAS}

Basturkmen, H. (2012). A genre-based investigation of discussion sections of research articles in Dentistry and disciplinary variation. Journal of English for Academic Purposes, 11(2). 134-144.

Bazerman, Ch. (1988). Shaping Written Knowledge: The Genre and Activity of the Experimental Article in Science. Colorado, EE.UU.: WAC Clearinghouse Landmark Publications in Writing Studies. Recuperado de http://wac.colostate.edu/books/bazerman_shaping

Bernstein, B. (1999). Vertical and Horizontal Discourse: an essay, British Journal of Sociology of Education, 20(2): 157-173.

Bhatia, V. (1993). Analysing genre: Language use in professional settings. London: Longman.

Ciapuscio, G. y Otañi, I. (2002). Las conclusiones de los artículos de investigación desde una perspectiva contrastiva, RILL, 15, 117-133.

Doran, Y. y Martin, J.R. Field relations: Understanding scientific explanations. En: K. Maton; J.R. Martin y Y, Doran. (Eds.), Teaching Science. Knowledge, Language, Pedagogy (pp. 105-133). London, U.K.: Routledge.

Eggins, S. y Martin, J.R. (2003). El contexto como género: una perspectiva lingüístico-funcional. Revista Signos, 36(54), 185-205.

Ghio, E. y Fernández, M.D. (2008). Lingüística Sistémico-Funcional. Aplicaciones a la Lengua Española. Santa Fe, Argentina: Universidad Nacional del Litoral.

Halliday, M.A.K. (1993). On the language of Physical Science. En M.A.K. Halliday y J.R. Martin. (Eds.), Writing science: Literacy and discursive power (pp. 54-68). Pittsburgh, EE.UU.: University of Pittsburgh Press.

Halliday, M.A.K. (2008). Complementarities in Language. Beijing, China: The Commercial Press.

Halliday, M.A.K. y Matthiessen, C.M.I.M. (2004). An Introduction to Functional Grammar, 3rd ed. London, U.K.: Arnold.

Hao, J. (2020). Analysing Scientific Discourse from a Systemic Functional Perspective: A framework for exploring knowledge building in biology. London, U.K.: Routledge. 
Hao, J. (2021). Building taxonomies: A discourse semantic model of entities and dimensionality in biology. En K. Maton; J.R. Martin y Y. Doran. (Eds.), Teaching Science. Knowledge, Language, Pedagogy (pp. 134-161). London, U.K.: Routledge.

Holmes, R. (1997). Genre Analysis, and the Social Sciences: An investigation of the Structure of Research Article Discussion Sections in Three Disciplines. English for Specific Purposes, 16(4), 321-337.

Hood, S. (2010). Appraising Research. Evaluation in Academic Writing. London, U.K.: Palgrave Macmillan.

Hood, S. y Martin, J.R. (2005). Invocación de actitudes: El juego de la gradación de la valoración en el discurso. Revista Signos, 38(58), 195-220.

Hopkins, A. y Dudley-Evans, T. (1988). A genre-based investigation of the discussion sections in articles and dissertations. English for Specific Purposes, 7, 113-122.

Hyland, K. (1999). Academic attribution: citation and the construction of disciplinary knowledge. Applied Linguistics, 20, 341-367.

Korner, H.; McInnes, D. y Rose, D. (2007). Science literacy. NSW, Australia: NSW AMES. Lemke, J. (1995). Making Trouble, Making Meaning. En Textual Politics: Discourse and Social Dynamics (pp. 154-184). London U.K.: Taylor \& Francis. Recuperado de http://www.jaylemke.com/storage/MakingTrouble1995.pdf

Martin, J.R. (1989). Factual writing. Exploring and challenging social reality. Oxford, EE.UU.: University Press.

Martin, J.R. (1992). English Text: System and Structure. Amsterdam, Holanda: Benjamins.

Martin, J.R. (1994). Macro-genres: the ecology of the page. Network 21, 29-52.

Martin, J.R. (1999). Modelling context: a crooked path of progress in contextual linguistics (Sydney SFL). En M. Ghadessy. (Ed.), Text and Context in Functional Linguistics (pp. 25-61). Amsterdam, Holanda: Benjamins (CILT Series IV).

Martin, J.R. (2008). Tenderness: realisation and instantiation in a Botswanan town. Odense Working Papers in Language and Communication, 30-62.

Martin, J.R. (2009). Boomer dreaming: the texture of recolonisation in a lifestyle magazine. En G. Forey y G. Thompson. (Eds.), Text-type and Texture (pp. 252-284). London, UK: Equinox Publishing.

Martin, J.R. (2013). Systemic Functional Grammar: A Next Step into the Theory. Axial Relations. Beijing, China: Higher Education Press. 
Martin, J.R. (2014). Evolving Systemic Functional Linguistics: beyond the clause. Journal of Functional Linguistics 1,3.

Martin, J. R. (2020). Revisiting filed: Specialized knowledge in secondary school science and humanities discourse. En J.R. Martin; K. Maton y Y. Doran. (Eds.), Accessing academic discourse: Systemic functional linguistics and legitimation code theory (p.p. 114-148). London, U.K.: Routledge.

Martin J.R. y Rose D. (2007). Working with Discourse. Meaning Beyond the Clause. London, U.K.: Continuum.

Martin J.R. y Rose, D. (2008). Genre Relations. Mapping culture. London, U.K.: Equinox. Martin, J.R. y White, P.P.R. (2005). The language of evaluation. Appraisal in English. London, U.K.: Palgrave.

Martin, J.R. y Matruglio, E. (2020). Revisiting mode: Context in/dependency in Ancient History classroom discourse. En J.R. Martin.; K. Maton y Y. Doran. (Eds.), Accessing academic discourse: Systemic functional linguistics and legitimation code theory (p.p. 89-113). London, U.K.: Routledge.

Matthiessen, C. y Halliday, M.A.K. (2009). Systemic functional grammar: A first step into the theory. Beijing, China: Higher Education Press.

Moyano, E.I. (2011). La Discusión de los artículos de investigación en el área de la agronomía: reconsideración de su estructura desde el análisis del discurso. En L. Barbara, y E.I. Moyano. (Eds.), Textos y lenguaje académico. Exploraciones sistémicofuncionales en portugués y español (pp.169-200). Los Polvorines, Argentina: Universidad Nacional de General Sarmiento.

Moyano, E.I. (2014). La Discusión en artículos de Microbiología: género, compromiso y construcción del conocimiento. Revista Onomázein, Número Especial IX ALSFAL (2014), 161-185.

Moyano, E.I. (2015a). La sección Discusión del artículo científico como género: Construcción del nuevo conocimiento y construcción del autor (Tesis doctoral). Universidad de Buenos Aires, Argentina.

Moyano, E.I. (2015b). Patrones de realización de la proyección en la Discusión de artículos de investigación producidos en español. DELTA: Documentação e Estudos em Linguística Teórica e Aplicada, 31(1), 143-183. 
Moyano, E.I. (2019). Knowledge construction in Discussions of research articles in two disciplines in Spanish: The role of resources of APPRAISAL. Journal of Pragmatics 139 (2019), 231-246.

Moyano, E.I. (en prensa). Descripción de géneros para su enseñanza en un Programa de Escritura Académica. Hacia la Deconstrucción Conjunta. En N. Ávila. (Ed.), Contribuciones multilingües a la investigación en escritura: Hacia un intercambio académico igualitario. Colorado, EE.UU.: WAC Colostate.

Peacock, M. (2002). Communicative moves in the discussion section of research articles. System, 30(4), 479-497.

Peng, J. (1987). Organizational features in chemical engineering research articles. English Language Research Journal, 1, 79-116.

Puiati de Gómez, H. (2005). El artículo de investigación científica. En Cubo de Severino, L. (Coord) Los textos de la ciencia. Principales clases del discurso académico-científico (pp. 23-92). Córdoba, Argentina: Comunicarte.

Swales, J. (1990). Genre analysis. English in academic and research settings. Cambridge, U.K.: Cambridge University Press.

Vidal Lizama, M. (2020). Aproximación al ensayo académico como género de formación en Ciencias Sociales: el caso de Sociología. DELTA: Documentação e Estudos em Linguística Teórica e Aplicada, 36(4), 1-26.

\section{DATOS PRIMARIOS}

(A01) Sheneiter, O; Fontana, S; Andrés, A. \& Rosso, B. (2006). Efecto del manejo de la defoliación sobre la acumulación de forraje y persistencia de dos cultivares de Trifolium pratense. Rev. Arg. Prod. Anim, 26, 11-21.

(A02) Jaurena, J. (2008). Contribución de la inoculación bacteriana a la fermentación de silajes de planta entera de maíz y sorgo. Rev. Arg. Prod. Anim. 28 (1), 21-29. 